\title{
COVID-19 infection in type 1 diabetes: emerging data
}

Cesare Miranda, Elena Rinaldo, Giorgio Zanette

Clinic of Endocrinology and Metabolism Diseases, Pordenone Hospital, Azienda Sanitaria Friuli Occidentale, Italy

Submitted: 11 January 2021

Accepted: 1 March 2021

Arch Med Sci Atheroscler Dis 2021; 6: e3-e4

DOI: https://doi.org/10.5114/amsad.2021.105064

Copyright @ 2021 Termedia \& Banach

Type 2 diabetes mellitus is one of the most common comorbidities associated with COVID-19. Furthermore, people with type 2 diabetes infected with SARS-CoV-2 have higher hospitalization and mortality rates [1].

Most publications do not distinguish between type 1 and type 2 diabetes, so evidence relating to the spread of COVID-19 infection in type 1 diabetes is limited, but new data are emerging.

At the time of writing (7 January 2021), 77,291 Italian citizens have died from SARS-CoV-2, and the prevalence of type 2 diabetes mellitus was $29.1 \%$ from the medical record analysis of 5962 deaths, while we do not know the prevalence of type 1 diabetes [2].

In a cross-sectional observation conducted in Alghero, Sardinia, one of the places with the highest concentrations of type 1 diabetics in the world, only 1 case was reported, which was easily treatable [3].

In England, in the largest full-population study linked to COVID-19, 364 people with type 1 diabetes died in hospital [4]. People with type 1 diabetes had a 3.5-fold greater risk of dying in hospital the non-diabetic population, while people with type 2 diabetes had a 2 -fold greater risk than the non-diabetic population [4].

In a related article, the same authors showed that in people with type 1 diabetes the risk of mortality was higher in patients with poor glycaemic control (glycosylated haemoglobin $\left(\mathrm{HbA}_{1 c}\right)>10 \%, 86 \mathrm{mmol} / \mathrm{mol}$ ), and they found a relationship between body mass index (BMI) and U-shaped mortality, with a nadir at a BMI of $25.0-29.9 \mathrm{~kg} / \mathrm{m}^{2}$ [5].

The death rate from COVID-19 for people with type 1 diabetes under the age of 50 years was so low that these figures were not included in the study. The authors found independent associations between age, gender, non-white ethnicity, socioeconomic status, and some comorbidities (renal impairment, heart failure, stroke) in people with type 1 diabetes.

In the CORONADO study [6] in a cohort of 1317 diabetic subjects admitted to hospital with COVID-19, the prevalence of type 1 diabetes was $3 \%$ (39 subjects). There were no deaths among subjects with type $1 \mathrm{DM}$ under the age of 65 years, and no association was found between $\mathrm{HbA}_{1 \mathrm{c}}$ (> $9 \%, 75 \mathrm{mmol} / \mathrm{mol}$ ) and the primary outcome, while BMI was a factor independent adverse prognostic for COVID-19 severity, analogous to what happens in the general population.

In the USA, in a prospective cohort study [7], people with type 1 diabetes had a 3.9-fold higher risk of hospitalization than non-diabetic people and a 3.35-fold increased risk of disease severity higher than non-diabetic people. Risk factors for disease severity were higher $\mathrm{HbA}_{1}$, hypertension, black race, and less use of diabetes technology.

\author{
Corresponding author: \\ Dr. Cesare Miranda \\ Clinic of Endocrinology \\ and Metabolism Diseases \\ Pordenone Hospital \\ Azienda Sanitaria Friuli \\ Occidentale, Italy \\ Phone: +39-034399051 \\ E-mail: cesare.miranda@tin.it
}


In a cross-sectional study of subjects with type 1 diabetes and laboratory-confirmed COVID-19 from 52 clinical sites in the United States, Ebekozien et al. [8] showed that the risk of diabetic ketoacidosis in black non-Hispanic patients is 3.7-fold higher than in white non-Hispanic patients.

In Belgium, in a retrospective study of a cohort of 2336 subjects with type 1 diabetes, only 5 older patients with type 1 diabetes required hospitalization, and no association with glucose control was found with the profile of comorbidities or the use of ACE/ARB [9].

Data in the literature, mostly derived from small retrospective studies, with the exception of the cohort study conducted in the UK $[4,5]$, seem to confirm a low incidence of SARV-COV-2 in people with type 1 diabetes and favourable prognosis in young people and adults under the age of 65 years.

According to Pitocco et al. [10], the low incidence of SARS-COV-2 in patients with type 1 diabetes could be linked with the younger age of type 1 diabetic subjects, while the favourable prognosis in people with type 1 diabetes under the age of 65 years could be linked to a lower prevalence of micro- and macrovascular complications.

On the other hand, in people with type 1 diabetes over the age of 65 years, and in the presence of comorbidities such as chronic kidney disease and history of hospitalization for stroke or heart failure, the risk of mortality from COVID-19 increases 3.5 -fold compared to the general population $[4,5]$.

Sardu et al. [11] demonstrated that during hospitalization, early normalization of blood glucose from intravenous insulin therapy in subjects with type 2 diabetes is associated with a reduction in mortality, inflammation, and coagulation, while in subjects with type 1 diabetes and SARS-COV-2 we have no data on the impact of early glycaemic control on in-hospital mortality.

In this short review, we summarize existing and daily growing data on the impact of COVID-19 infection in patients with type 1 diabetes.

We believe there is still a significant gap on this issue because the data are from retrospective studies obtained from electronic medical records, which are often inaccurate and have missing data [12].

The purpose of our letter to the editor is to call on researchers from around the world to conduct prospective studies on this topic with systematic data collection and extensive follow-up to better understand the real risk of spreading COVID-19 infection in patients with type 1 diabetes and whether the treatment of predictive mortality factors such as BMI and glycaemic control could influence outcomes in type 1 diabetes.

\section{Conflict of interest}

The authors declare no conflict of interest.

\section{References}

1. Zhu N, Zhang D, Wang W, et al.; China Novel Coronavirus Investigating and Research Team. A novel Coronavirus from patients with pneumonia in China, 2019. N Engl J Med 2020; 382: 727-33.

2. Istituto Superiore Sanità. Characteristics of SARS-CoV-2 patients dying in Italy.Report based on available data on December $16^{\text {th }}, 2020$. Available from https://www. epicentro.iss.it/coronavirus/bollettino/Bollettino-sorveglianza-integrata-COVID-19_4-ottobre\%202020.pdf. Accessed January 7, 2021.

3. Tatti P, Tonolo G, Zanfardino A, lafusco D. Is it fair to hope that patients with type 1 diabetes (autoimmune) may be spared by the infection of Covid-19? Med Hypotheses 2020; 142: 109795.

4. Barron E, Bakhai C, Kar P, et al. Associations of type 1 and type 2 diabetes with COVID-19-related mortality in England: a whole-population study. Lancet Diabetes Endocrinol 2020; 8: 813-22.

5. Holman N, Knighton P, Kar P, et al. Risk factors for COVID-19-related mortality in people with type 1 and type 2 diabetes in England: a population-based cohort study. Lancet Diabetes Endocrinol 2020; 8: 823-33.

6. Cariou B, Hadjadj S, Wargny $M$, et al.; CORONADO investigators. Phenotypic characteristics and prognosis of inpatients with COVID-19 and diabetes: the CORONADO study. Version 2. Diabetologia 2020; 63: 1500-15.

7. Gregory JM, Slaughter JC, Duffus SH, et al. COVID-19 severity is tripled in the diabetes community: a prospective analysis of the pandemic's impact in type 1 and type 2 diabetes. Diabetes Care 2021; 44: 526-32.

8. Ebekozien O, Agarwal S, Noor N, et al. Full inequities in diabetic ketoacidosis among patients with type 1 diabetes and COVID-19: data from 52 US clinical centers. J Clin Endocrinol Metab 2021; 106: e1755-62.

9. Vangoitsenhoven R, Martens PJ, van Nes F, et al. No evidence of increased hospitalization rate for COVID-19 in community-dwelling patients with type 1 diabetes. Diabetes Care 2020; 43: e118-9.

10. Pitocco D, Tartaglione L, Viti L, et al. Lack of type 1 diabetes involvement in SARS-CoV-2 population: only a particular coincidence? Diabetes Res Clin Pract 2020; 164 108220.

11. Sardu C, D'Onofrio N, Balestrieri ML, et al. Outcomes in patients with hyperglycemia affected by COVID-19: can we do more on glycemic control? Diabetes Care 2020; 43: 1408-15.

12. Selvin E, Juraschek SP. Diabetes epidemiology in the COVID-19 pandemic. Diabetes Care 2020; 43: 1690-4. 